\title{
A Software for Dimensioning of Small Microgrids with PV-Battery Systems
}

\author{
Jose Luis Torres-Moreno ${ }^{1,2}$, José Antonio Carballo ${ }^{3}$, Javier Bonilla ${ }^{3}$ and Antonio Giménez ${ }^{1,2}$ \\ ${ }^{1}$ CIESOL-University of Almería, Almería (Spain) \\ ${ }^{2}$ Agrifood Campus of International Excellence, ceiA3, Almería (Spain) \\ ${ }^{3}$ CIEMAT - Plataforma Solar de Almería, Almería (Spain)
}

\begin{abstract}
The new developments of more efficient photovoltaic panels, batteries, inverters and their control systems are increasing the number of home renewable energy installations worldwide. Since a high part of the household demand arises at night, it is reasonable to consider the installation of batteries along with the photovoltaic systems. However, their acquisition costs still remain considerably high, and hence, a deficient selection of their capacity may reduce drastically the profitability of the renewable facility. At the same time, the number of solar panels to be installed is regarded by the batteries size, leading to a challenging task of dimensioning. For this purpose, we have developed a software which supports to select the most convenient characteristics of the elements to install in a low scale microgrid with presence of photovoltaic panels and batteries. According to the simulation results, this software helps to optimize both the dimensioning of household or office buildings attending to different criteria as the profitability or the reduction of the $\mathrm{CO} 2$ emissions.
\end{abstract}

Key-words: Dimensioning, Optimization, Software, Micro-grid, Photovoltaic, Battery.

\section{Introduction}

It is well known that, in the last years, the installation of photovoltaic installation for self-consumption has increased considerably. However, due to the typical consumption patterns of residential customer, there exists a mismatch between the diurnal solar energy production and its consumption. In order to take maximum advantage of photovoltaic energy, storage arises as a good solution. Among the options to storage energy are mechanical, thermal, chemical or electrochemical systems. From a practical point of view and according to the state of development of the different technologies, only electrochemical batteries appear to be suitable for household installations. Even in commercial facilities and offices buildings, where the solar energy production usually matches the maximum consumption loads, the use of batteries may allow to reduce energetic costs (Merei et al., 2016). A typical configuration of PV-battery systems, often referred to as grid-connected DC-link setup, as described in (Riesen et al., 2017), consists in connecting the battery and photovoltaic panels together to the direct current (DC) input of the inverter, whereas another alternate current (AC) input allows power exchange with the public grid, and the inverter's AC output feeds the loads. A schematic of this setup is depicted in Fig. 1.

The use of batteries is not always desirable, from an economical point of view, as demonstrated in (Ahmad and Alam, 2018) by simulation studies using a commercial software, HOMER $®$, specifically designed to deal with microgrids. In those studies, two approaches were considered for reducing the energy cost in a campus: a PVBattery system and a grid-connected PV system. Whereas the first one lead to an increase of the energetic costs, the grid-connected solution resulted in a profitable option. In (Ren et al., 2016) the authors focused on the use of batteries in residential buildings. In this case, they found interesting alternatives for reducing the electricity costs by combining batteries with photovoltaic systems and tariff management. 


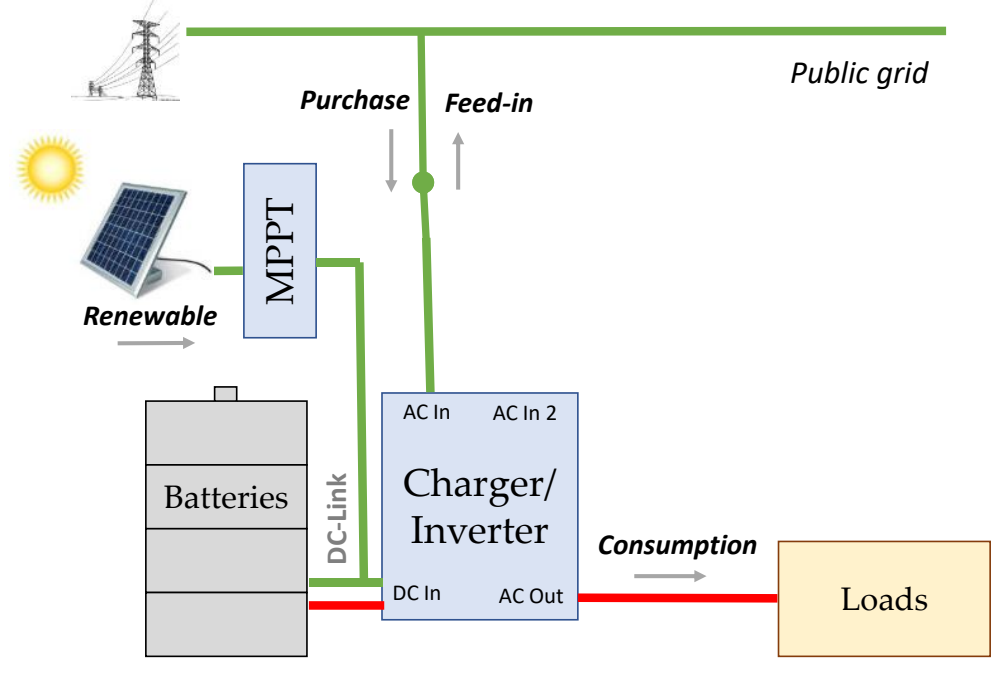

Fig. 1: DC-Link configured PV-Battery system

In (Barua et al., 2017) another study based on simulations using HOMER® considers the combined use of PVbattery system and diesel generator in a small rural area, leading to a reduction of emissions and cost of electricity with respect to the original configuration. A similar study was carried out in (Pavan Kumar and Bhimasingu, 2015) for an urban building with a priority load of $3.4 \mathrm{MWh} /$ day and a deferrable load of 3.3 Wh/day, leading to a solution comprising $600 \mathrm{~kW}$ of utility grid contribution, a PV system of $180 \mathrm{~kW}$, a wind energy system of $150 \mathrm{~kW}, 79.2 \mathrm{kWh}$ of storage and an inverter with a nominal power of $160 \mathrm{~kW}$. In (Traoré et al., 2018), a mathematical model of a microgrid including PV-battery systems and wind turbines is built to formulate a minimizing problem in which the cost function depends on the number of solar panels, the number of wind turbines and the size of the storage system, and the constraints are related to the reliability and power limits, and battery stored energy in addition to the energy and power balance. In that work, the optimization process is addressed by using genetic algorithms, as in $(\mathrm{Li}, 2019)$, in which a similar approach is considered for residential houses in Australia with grid-connected PV-Battery systems.

As another example of reduction of the cost of domestic electricity through an accurate selection of PV-battery systems, in (Constant et al., 2019) it is calculated that, for a household in North Midlands of England, the annual bill can be reduced around £115/year. The influence of an accurate dimensioning of household systems including storage for reducing the electricity cost is also demonstrated in (Sharma et al., 2019). However, in contrast with these works, in (Boeckl and Kienberger, 2019) it is proposed an alternative method for sizing PVBattery systems focusing only on technical consideration and, hence neglecting economic considerations.

In the previously mentioned works, it is not considered explicitly the energy management strategy (EMS) when formulating the problem of sizing the different microgrids components. This issue is regarded in (Rullo et al., 2019), in which the optimization problem uses an outer loop for sizing and an inner loop in charge of solving the EMS for each candidate solution. An example of work focusing exclusively on the EMS can be found in (Khakimova et al., 2017), in which model predictive control is used. A similar approach considering the EMS in the optimization problem is found in (Jamshidi and Askarzadeh, 2019), which deals with a PV, fuel cell and diesel generator microgrid in off-grid mode.

As can be seen, the problem of sizing microgrids still requires many research efforts since, on the one hand, new approaches may lead to greater benefits in reducing the electricity cost and pollution, and, on the other hand, the potential interest of end users in self-dimensioning their own PV-battery household systems before making any investment. For this reason, in this work we have developed an easy-to-use software to support the dimensioning of these kind of systems. The rest of the article is structured as follows: section 2 presents a typical EMS which is implemented in our software. Section 3 presents the software and optimization problems, while section 4 covers a case of study. Finally, conclusions are provided in section 5 . 


\section{Energy management}

In this section, we present the rules that typically, a domestic or an office installation as represented in Fig. 2, (whose schematics corresponds to that introduced in section 1) that govern the power exchanges between the different components of this kind of microgrids.

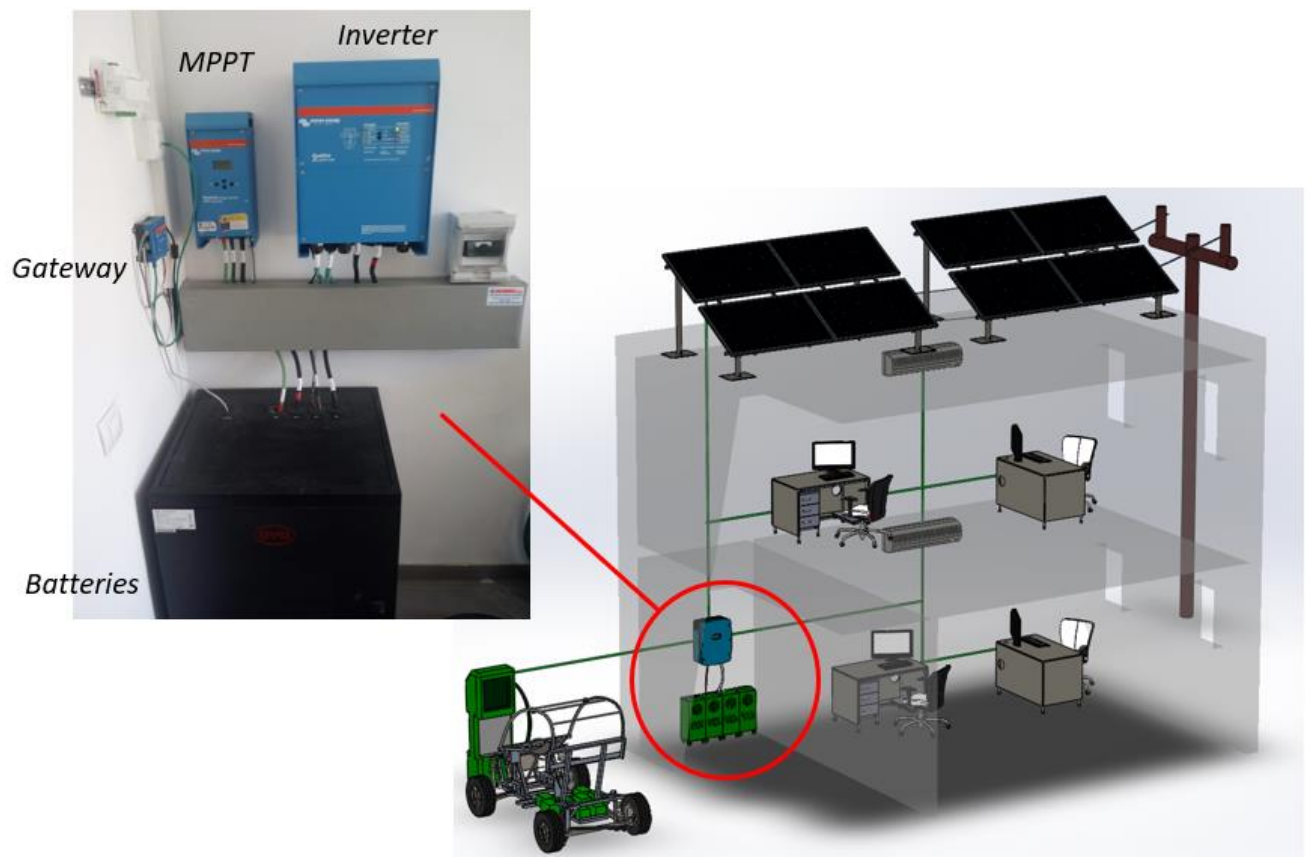

Fig. 2: A microgrid for a small office building. On the left side, it is represented the real equipment, whose characteristics can fit to an installation as the one depicted on the right side.

According to these rules, or energy management strategy, the described system needs a control unit in charge of the execution of the control energy strategy. In order to exploit the potential of batteries, it is often desirable to implement an energy storage system configuration. This configuration, with the selection of appropriate parameters, allows to establish priorities in the use of the resources to satisfy the demand in an efficient way (Torres-Moreno et al., 2018). In Fig. 3, a flowchart representing the sequence of is depicted.

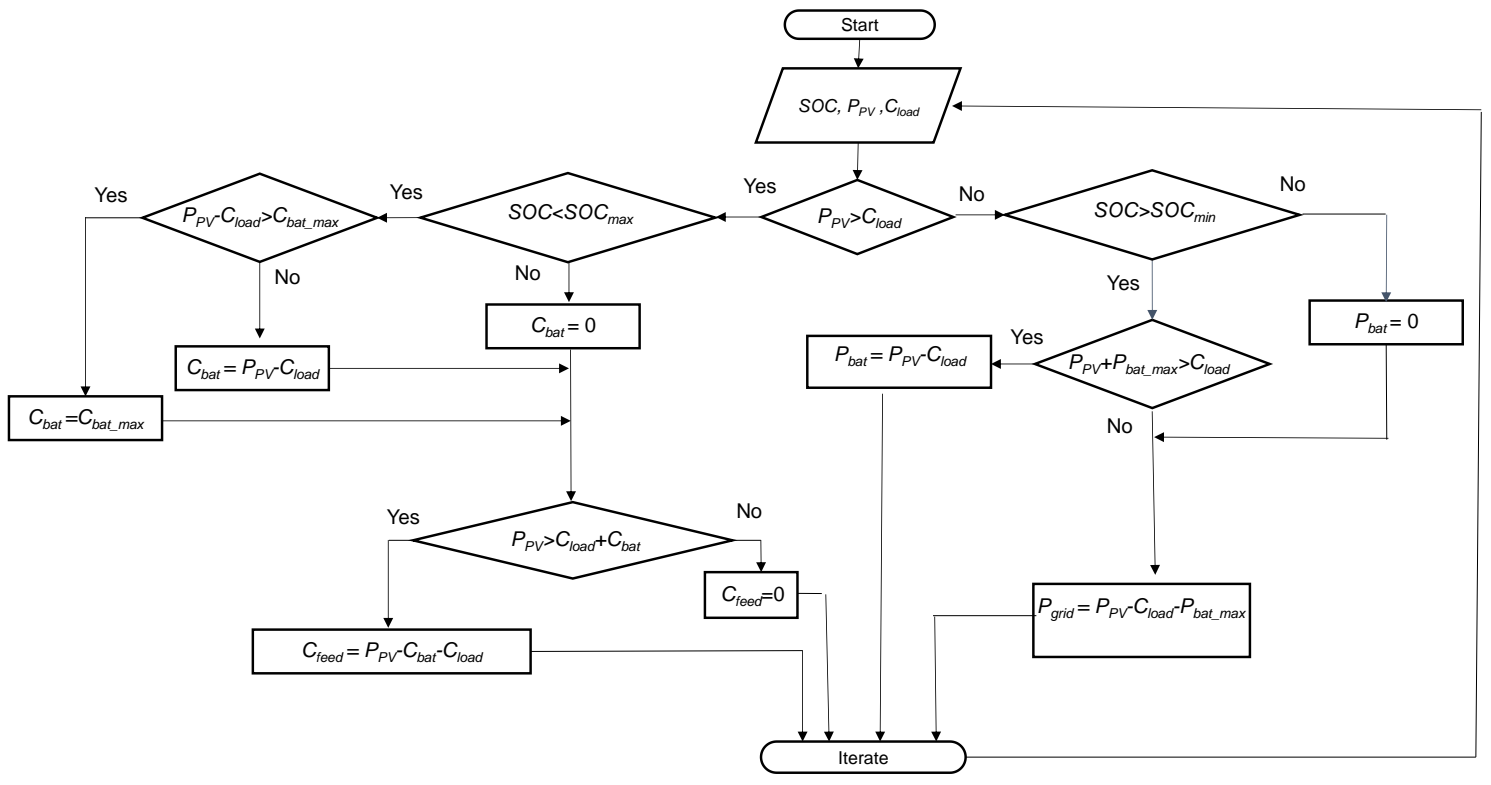

Fig. 3: Flowchart describing the power exchange rules in a typical household energy storage system. 
The control sequence, which is executed cyclically, is explained as follows: first, the control unit reads the batterie's state of charge (SOC), the power generated by the photovoltaic panels $\left(\mathrm{P}_{\mathrm{pv}}\right)$ and the power demand of the loads $\left(\mathrm{C}_{\text {load }}\right)$. If the power generated by the photovoltaic panels exceeds the loads, the power excess is used to charge the batteries if their state of charge is below the upper threshold $\left(\mathrm{SOC}_{\max }\right)$. In that case, or in case that the difference between the power generated by the photovoltaic panels and the loads is greater than the maximum batteries charging power, the exceeding power is feed into the public grid. On the other hand, if the power generated by the solar panels is insufficient to feed the loads, the energy from the batteries (when their state of charge is greater than the lower threshold, $\mathrm{SOC}_{\min }$ ) is used as an extra power contribution. Finally, if the available power in the PV-Battery system is lower than the demanded, the deficit will be covered by the public grid. According to these rules and taking into account predictions on both the load consumption and solar radiation, it is possible to estimate the power exchanges that will occur for a PV-Battery installation as a function of the number and characteristics of panels and batteries. This is the basis of the present work, in which it has been developed a software to support the PV-Battery systems sizing, and whose principles are described in the next section.

\section{The proposed software}

Considering the previous control rules, a flexible and easy to use algorithm for evaluation and design optimization has been developed. The main algorithm demands two inputs, the first one is the energy demand curve $\left(\mathrm{C}_{\text {load }}\right)$, the second is a vector that contains all the design parameters of the system $(\mathrm{X})$, see Fig. 4.

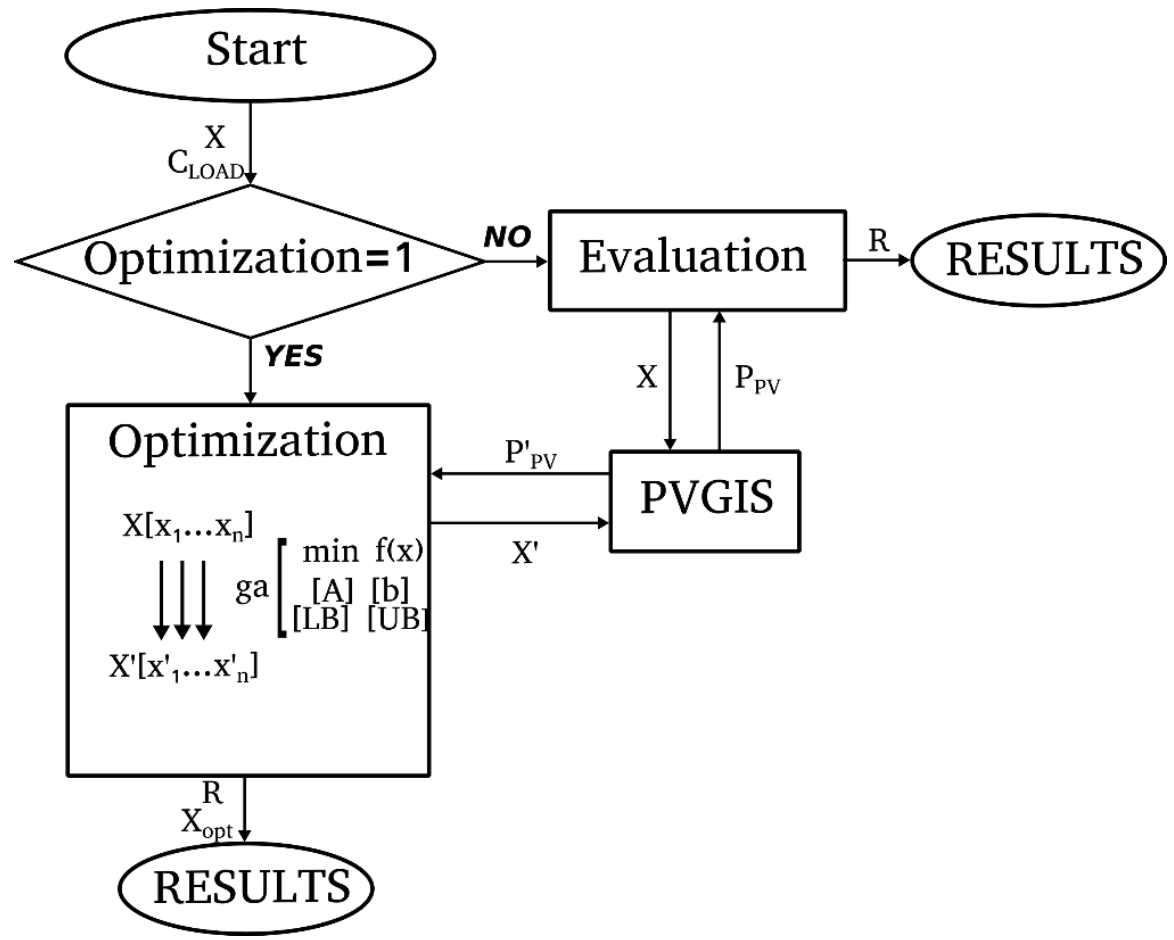

Fig. 4: Algorithm flowchart.

The design parameters input is composed by the values of latitude and longitude of the place, optimization period date, peak power of PV system, inclination and orientation of the pv system, storage system capacity, PV cost in $€ / \mathrm{kWp}$, batteries cost in $€ / \mathrm{kWh}$, electric power cost of the grid and the benefits of network discharges.

If the optimization option is not selected, the algorithm simulates the design parameters in vector $\mathrm{X}$ making a query to PVGIS API and obtaining the PV production ( $\mathrm{PpV}$ ) for the PV system. Them, considering the previous control rules, it is computed sequentially for every time step the use of the resources to satisfy the demand $\left(\mathrm{C}_{\text {load }}\right)$ and it is returned the results in a results matrix. This matrix is composed of several values computed: energy discharged to the grid (P1), energy stored in batteries (P2), energy consumed from the network (C1), 
energy consumed from the batteries (C2), energy consumed instantly (C4), battery status (SOC), daily cost of electricity consumed according to the valley-peak hourly discrimination (C1_cost), daily amortization cost of the photovoltaic generator (C_gen_pv) assuming a lifespan of 25 years, daily amortization cost of the battery system (C_bat) assuming a useful life of 10 years, discount in $\mathrm{C}_{-} \_$cost due to the energy discharged to red (C_P1), average daily cost of energy consumed (C_energy_cost, see eq 1.) computed as the sum of the four previous, total cost (C_total) and benefit for self-production, generation of $\mathrm{kg} \mathrm{CO}_{2}$.

$$
C_{\text {energy }_{\text {cost }}}=C 1_{\text {cost }}+C_{g e n_{p v}}+C_{b a t}+C_{P 1}
$$

On the contrary, if the optimization option is selected, a design optimization based on an artificial intelligence (AI) technique known as genetic algorithm (ga) optimization is carried out. The (ga) optimization is an optimization method based on biological evolution in where the algorithm modifies (crossover and mutation) some of individuals selected from a previous population at each step called generation. After successive generations the population evolves to an optimal solution. In this case, the genetic algorithm modifies the design parameters contained in X successively under certain restrictions ([b], [LB], [UB]) according to one or some criteria (multi-objective optimizations) calculated using the evaluation function. Vector [b] defines equality restrictions and inequality conditions ranges are defined by lower and higher values vectors ([LB], [UB]) respectively. Note that any value of the results computed by the evaluation function and described previously can be used as criteria by the proposed algorithm. Once the optimization is finished, the algorithm returns the optimal configuration and graphs with the optimized system results.

Furthermore, a graphical user interface, where configuration parameters can be set, has been developed in order to easily define the optimization problem (see Fig. 5).

(15OL) -

DATE TIME

Ini Year

Fin Year

Ini Month

Final Month

Ini Day

Final Day

Sample time

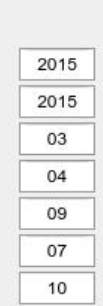

OPTIMIZATION

Components

Optimal Aspect

Optimal Inclination

Generations

Population

RESULTS
DESIGN

PV peak

Bat storage

Loss

Tracking Type

Aspect

Inclination

PV Tech

Mounting Place

$\cos T$

PV cost

Bat cost

Electric low cost

Electric high cost

Electric spill cost
LOCATION

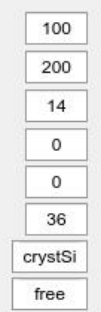

Latitude

$0 \bigcirc 1$

RUN

Longitud

Simulation / Optimization

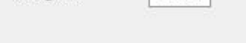

(azation
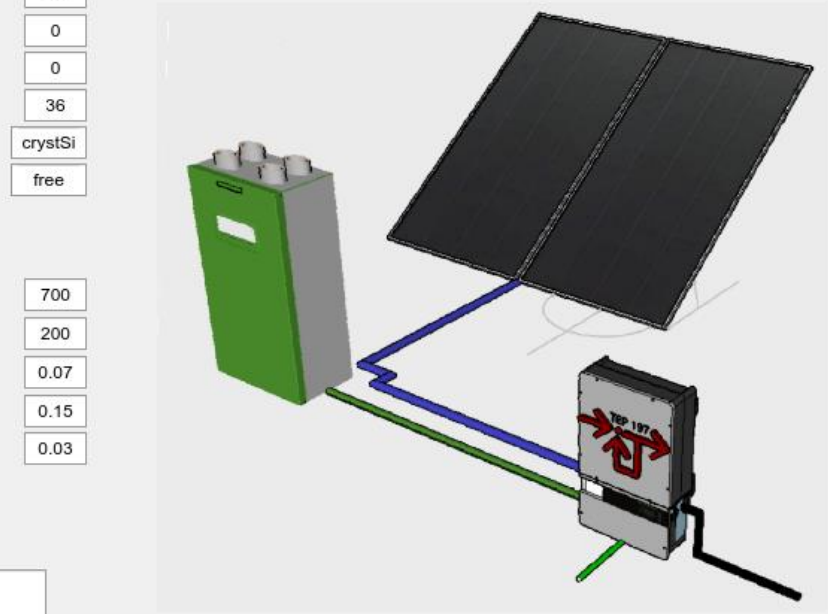

Running...

Fig. 5: GUI layout. 


\section{A case of study}

In this work it has been considered the energy consumption data corresponding to a single-family house located in Spain (lat: 37.0482207, long:-2.3626499). The historical data series provided by the energy company responsible for the electric supply includes data from August to July of the following year. In Fig. 6 it is depicted the consumption across the year of study (left) and the hourly consumptions of two typical days in summer and winter time (right).
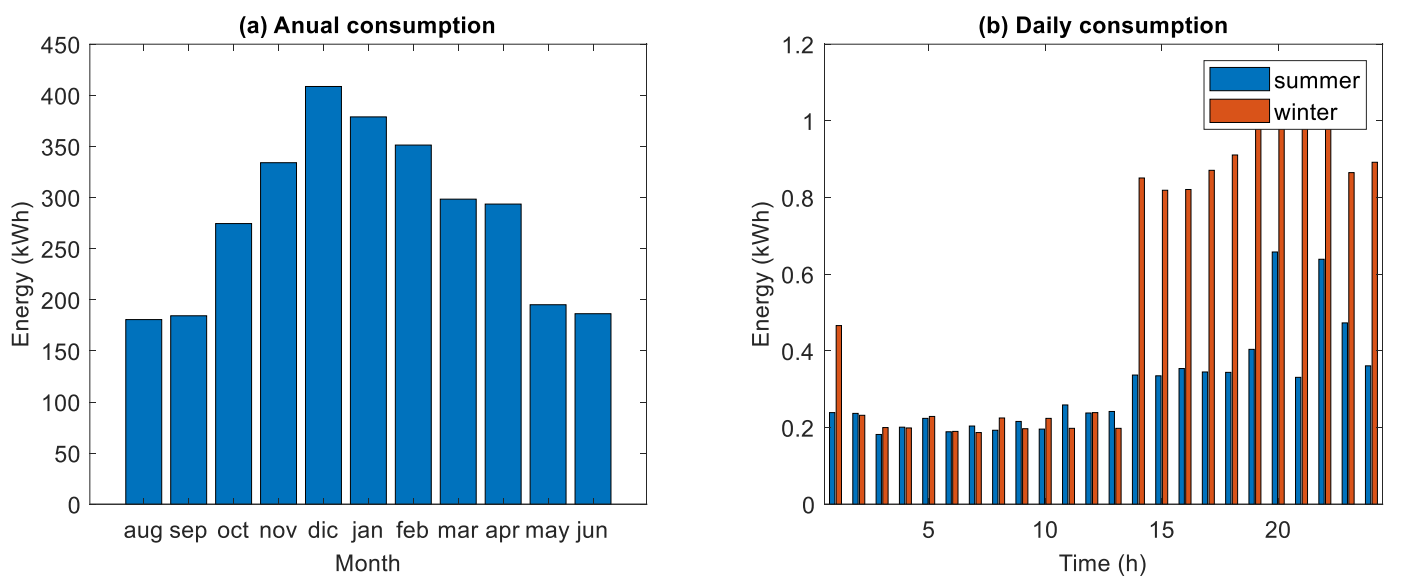

Fig. 6: Energy consumption of the house analyzed.

In this example, the PV peak power, energy storage capacity, inclination and orientation of the PV system have been selected as optimizable design parameters. Inclination and orientation of the PV system have been limited between $[0,90]$ degrees in elevation and [-90,90] degrees in azimuth (East-West), also elevation and orientation values have been restricted to integer values, reducing the optimization decision space and therefore the optimization time.

The objective function defined is Minimize C_energy_cost, as commented before the criterion C_energy_cost considers the energy consumption cost, the PV and battery system costs according to 25 and 10 years of useful life respectively and the discount in the energy cost due to the energy discharged to the grid. Note that the energy discharged to the grid discount is limited by the total cost of energy consumed. The algorithm has been configured with costs predicted for 2025 (see Tab. 1) and a time resolution of 30 minutes.

Tab. 1: 2025 Costs (Merei et al., 2016).

\begin{tabular}{ll}
\hline PV costs & $800 € / \mathrm{kWp}$ \\
Battery Costs & $375 € / \mathrm{kW} \mathrm{h}$ \\
Electricity consumed peak price* & $0.25 € / \mathrm{kW} \mathrm{h}$ \\
Electricity consumed valley price* & $0.22 € / \mathrm{kW} \mathrm{h}$ \\
Electricity discharged price & $0.0025 € / \mathrm{kW} \mathrm{h}$
\end{tabular}

*Peak 20-8 h, Valley 8-20 h

The genetic algorithm has been configured with 25 generations with 10 individuals by generation. Fig. 7 shows the evolution of the optimization process and how the optimal solution does not substantially improve the criteria values (best and mean criteria values in each generation) after the generation 10, therefore with this configuration the genetic algorithm has converged into an optimal solution in less than 16 generations. 


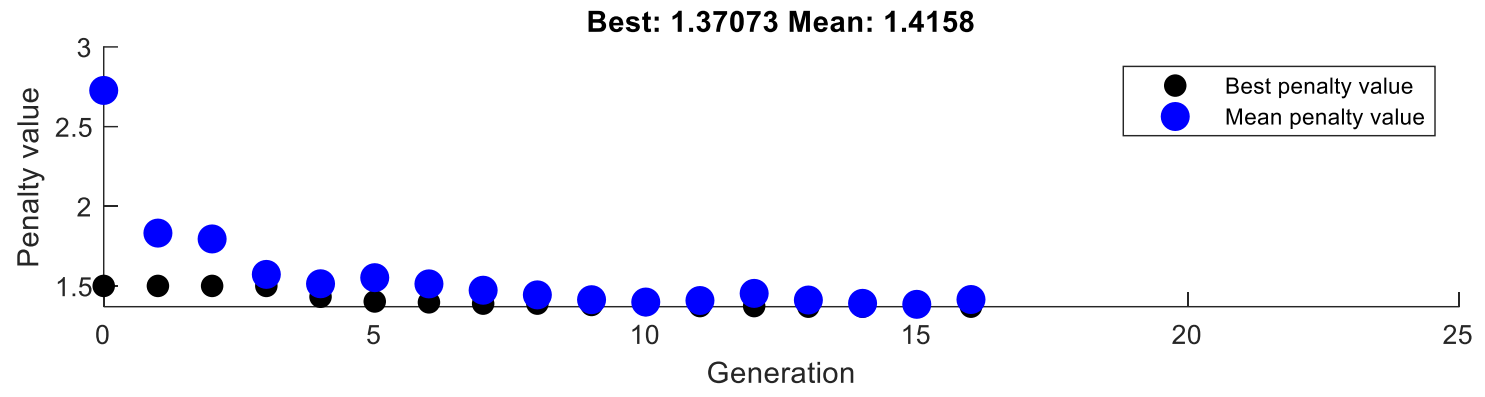

Fig. 7: Optimization process.

The system configuration optimized (see Tab. 2) will produce $12477 \mathrm{kWh}$ per year, to meet a total yearly demand of $3325 \mathrm{kWh}$, with a contribution from the network of $1200 \mathrm{kWh}$ (Fig. 8). Furthermore, the algorithm estimates that the daily energy cost of the single-family house studied can be reduced from $2.3 €$ /day to 1.4 $€ /$ day with the PV-battery system optimized. The results represent a reduction of the energetic cost of $39 \%$ during the life of the PV-battery system if the prices considered are kept constant.

Tab. 2: Optimization results.

\begin{tabular}{ll}
\hline PV systems size & $8.6 \mathrm{kWp}$ \\
Inclination & $31^{\circ}$ \\
Orientation* & $-22^{\circ}$ \\
Battery system size & $3.7 \mathrm{~kW} \mathrm{~h}$ \\
\hline
\end{tabular}

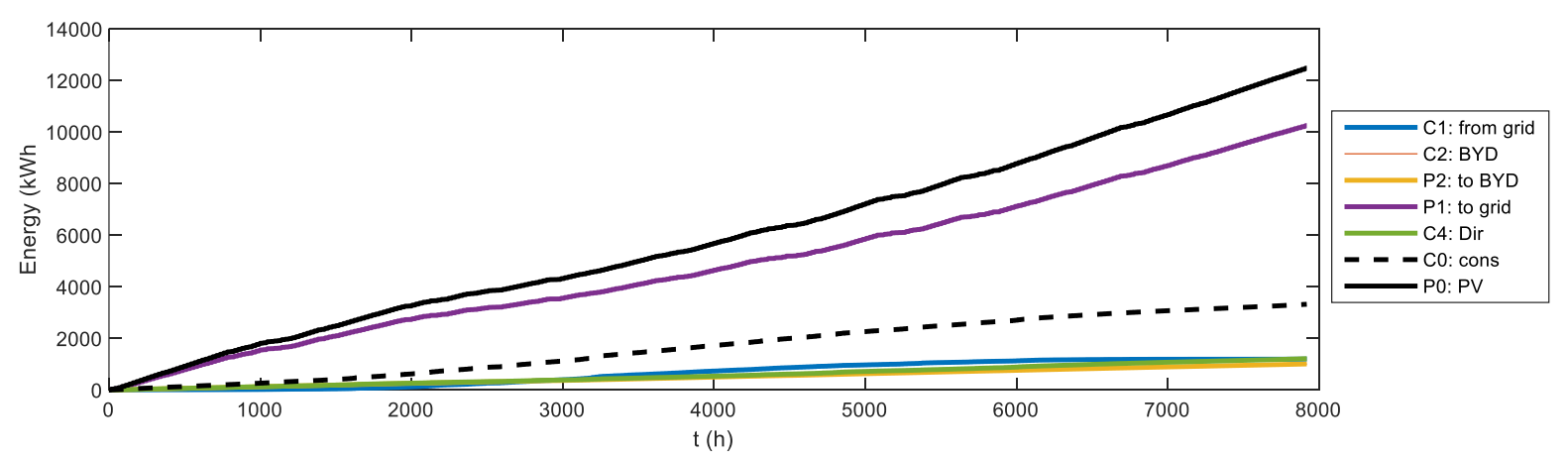

Fig. 8: Total system behavior.

Fig. 9 and Fig.10 show the optimized system behavior during the autumn equinox week and winter solstice week, for the energy management strategy described in section 2. In both, most of the energy produced by the PV generator is spilled to the network after fully charges the battery system and supplies the instant consumption. The battery system supplies most of the energy demanded in the hours without sun during the autumn equinox, on the contrary in the winter solstice a great contribution from the network is necessary. The PV system is oriented to the East ( $-22^{\circ}$ from South) minimizing the energy consumption from the network in the initial hours of the days, when the battery system is exhausted. 


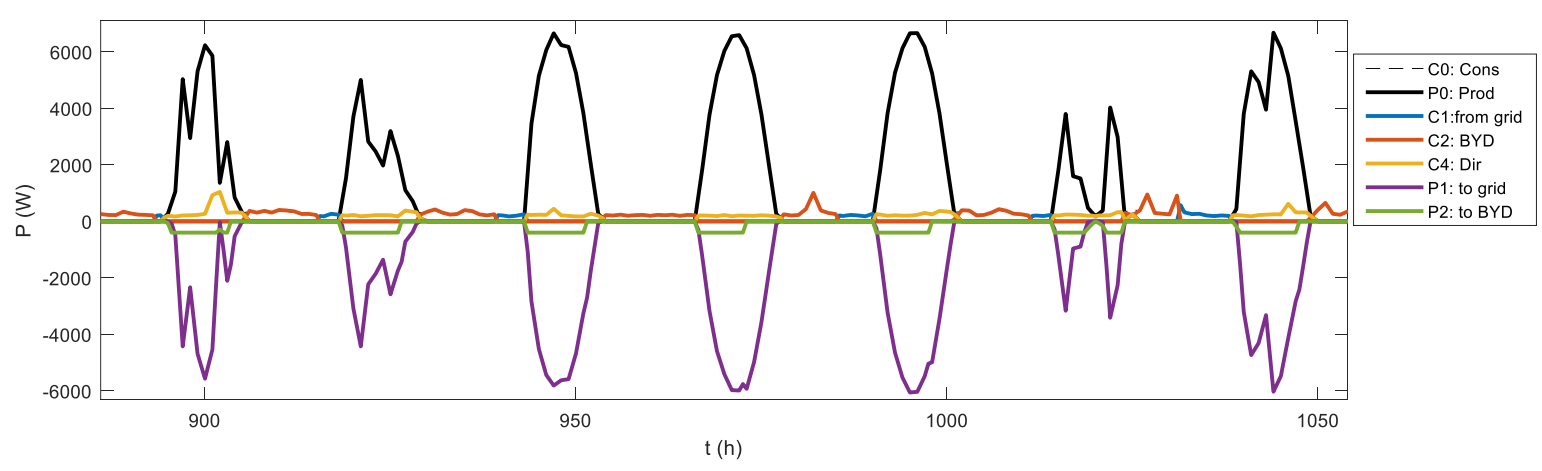

Fig. 8: Autumn equinox week.

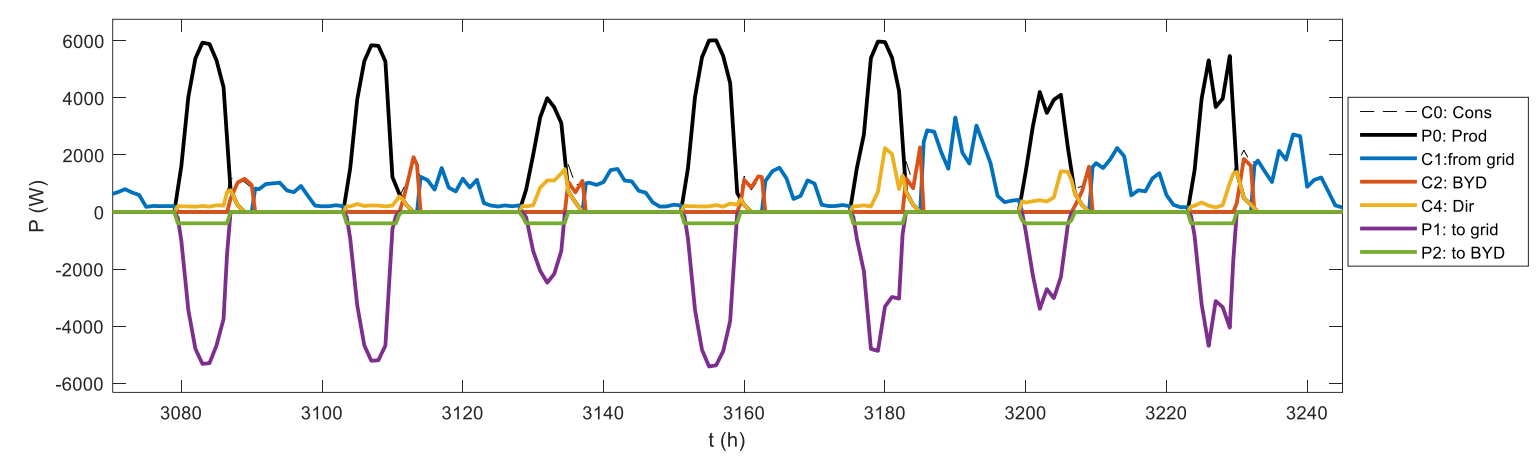

Fig. 9: Winter solstice week.

\section{Conclusions}

This paper presents a methodology for smart dimensioning of low scale microgrids including photovoltaic energy and batteries storage. This methodology has been implemented in a software which provides a graphical user interface that allows to non-specialized programmers to easily configure the parameters needed to obtain an economic assessment of the different possible configurations. As an output, the user receives the PV systems size, inclination, orientation and battery system size which best fit the requirements. The software implements an energy management strategy, presented in section 2, and referred to as energy storage system, which is present in some commercial equipment. In order to test the software, a case of study has been addressed in section 4. For this purpose, the consumption data of a typical house in the southern Spain has been introduced as input. According to the obtained results, the software gives a solution which could help to reduce the domestic energy cost in a $39 \%$. As future works, the software is aimed to be implemented in fully open-source platforms and publicly available. In addition, new features will be included as dynamical energy management strategy based on artificial intelligence.

\section{Acknowledgments}

This work has been funded by the National R+D+i Plan Project DPI2017-85007-R of the Spanish Ministry of Science, Innovation and Universities and ERDF funds.

\section{References}

Ahmad, F., Alam, M.S., 2018. Optimal Sizing and Analysis of Solar PV, Wind, and Energy Storage Hybrid System for Campus Microgrid. Smart Sci. 6, 150-157. https://doi.org/10.1080/23080477.2017.1417005

Barua, A., Jain, A.K., Gupta, M., Mishra, P.K., 2017. Control and techno-economic analysis of PV-diesel- 
battery based hybrid microgrid system, in: 2017 Conference on Information and Communication Technology (CICT). IEEE, pp. 1-5. https://doi.org/10.1109/INFOCOMTECH.2017.8340610

Boeckl, B., Kienberger, T., 2019. Sizing of PV storage systems for different hou sehold types. J. Energy Storage 24, 100763. https://doi.org/10.1016/j.est.2019.100763

Constant, E., Thanapalan, K., Bowkett, M., 2019. System Sizing for Solar Powered Sustainable Energy System Designed for Domestic Users. Renew. Energy Power Qual. J. 17, 172-176. https://doi.org/10.24084/repqj17.254

Jamshidi, M., Askarzadeh, A., 2019. Techno-economic analysis and size optimization of an off-grid hybrid photovoltaic, fuel cell and diesel generator system. Sustain. Cities Soc. 44, 310-320. https://doi.org/10.1016/j.scs.2018.10.021

Khakimova, A., Kusatayeva, A., Shamshimova, A., Sharipova, D., Bemporad, A., Familiant, Y., Shintemirov, A., Ten, V., Rubagotti, M., 2017. Optimal energy management of a small-size building via hybrid model predictive control. Energy Build. 140, 1-8. https://doi.org/10.1016/j.enbuild.2017.01.045

Li, J., 2019. Optimal sizing of grid-connected photovoltaic battery systems for residential houses in Australia. Renew. Energy 136, 1245-1254. https://doi.org/10.1016/j.renene.2018.09.099

Merei, G., Moshövel, J., Magnor, D., Sauer, D.U., 2016. Optimization of self-consumption and technoeconomic analysis of PV-battery systems in commercial applications. Appl. Energy 168, 171-178. https://doi.org/10.1016/j.apenergy.2016.01.083

Pavan Kumar, Y. V., Bhimasingu, R., 2015. Renewable energy based microgrid system sizing and energy management for green buildings. J. Mod. Power Syst. Clean Energy 3, 1-13. https://doi.org/10.1007/s40565-015-0101-7

Ren, Z., Grozev, G., Higgins, A., 2016. Modelling impact of PV battery systems on energy consumption and bill savings of Australian houses under alternative tariff structures. Renew. Energy 89, 317-330. https://doi.org/10.1016/j.renene.2015.12.021

Riesen, Y., Ballif, C., Wyrsch, N., 2017. Control algorithm for a residential photovoltaic system with storage. Appl. Energy 202, 78-87. https://doi.org/10.1016/j.apenergy.2017.05.016

Rullo, P., Braccia, L., Luppi, P., Zumoffen, D., Feroldi, D., 2019. Integration of sizing and energy management based on economic predictive control for standalone hybrid renewable energy systems. Renew. Energy 140, 436-451. https://doi.org/10.1016/j.renene.2019.03.074

Sharma, V., Haque, M.H., Aziz, S.M., 2019. Energy cost minimization for net zero energy homes through optimal sizing of battery storage system. Renew. Energy 141, 278-286. https://doi.org/10.1016/j.renene.2019.03.144

Shaughnessy, E.O.', Ardani, K., Cutler, D., Margolis, R., 2017. Solar Plus: A Holistic Approach to Distributed Solar PV. Golden, CO (United States). https://doi.org/10.2172/1364033

Torres-Moreno, J., Gimenez-Fernandez, A., Perez-Garcia, M., Rodriguez, F., 2018. Energy Management Strategy for Micro-Grids with PV-Battery Systems and Electric Vehicles. Energies 11, 522. https://doi.org/10.3390/en11030522

Traoré, A., Elgothamy, H., Zohdy, M.A., 2018. Optimal Sizing of Solar/Wind Hybrid Off-Grid Microgrids Using an Enhanced Genetic Algorithm. J. Power Energy Eng. 6, 64-77. https://doi.org/10.4236/jpee.2018.65004 